\title{
Commentary: The hybrid option expands the cardiac surgical portfolio
}

\section{Richard J. Shemin, MD}

In JTCVS Techniques, Harloff and colleagues ${ }^{1}$ describe "hybrid valve-in-valve mitral valve replacement." They describe a clinical case of a failed stenotic pericardial mitral valve in a high-risk frail female patient. She had her original mitral valve replacement 9 years previously via a minimally invasive right thoracotomy.

A subset of cardiac surgeons has acquired advanced interventional skills, primarily with transcatheter aortic valve replacement (TAVR) valves. In addition to TAVR, which has become the procedure of choice for calcific aortic stenosis, percutaneous valve-in valve procedures have become an evidence-based standard for failed bioprosthetic valves. The procedure obviates the need for a repeat sternotomy for an aortic or mitral valve procedure. Creative use of a TAVR valve-in-valve procedure to replace a failed surgical bioprosthetic valve via an open surgical procedure should be considered in appropriate patients.

Valve-in-valve procedures in the mitral position require special consideration. The feasibility and clinical success have been demonstrated. However, the need to evaluate the potential for creating left ventricular outflow tract obstruction due to leaflet tissue being forced into the left ventricular outflow tract is essential in the preoperative planning. Preoperative computed tomography images with a simulated TAVR valve can predict the likelihood of this complication.

The advantage of an open approach is direct visualization of the failed surgical valve and the removal of the leaflet(s)

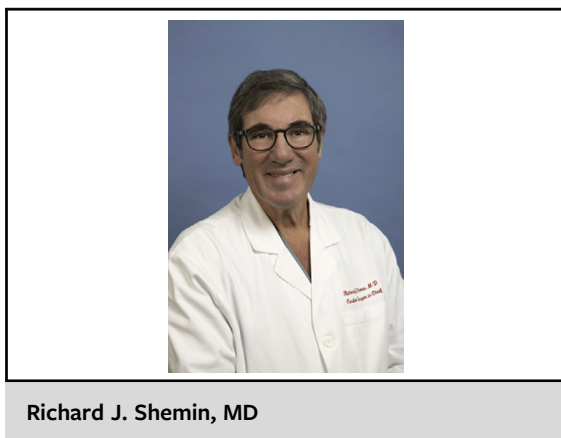

CENTRAL MESSAGE

Surgical creativity and novel approaches with interventional hybrid procedures.

combined with a $20 \% / 80 \%$ positioning of the transcatheter valve in relation to the mitral annular plane. The removal of the surgical valve is not required. One can achieve secure fixation, prevention of perivalvular leak, and the prevention of left ventricular outflow tract obstruction.

The importance of this paper is to stimulate our creativity. It clearly demonstrates that we can capitalize on our interventional skills to extend options for safe and effective redo operations on high-risk and frail patients. Aortic crossclamp and cardiopulmonary bypass times are significantly reduced, along with the morbidity associated with conventional redo procedures. We should embrace these advances and the options these procedures will provide our patients.

\section{Reference}

1. Harloff M, Papoy A, Aghayev A, Kaneko T. Hybrid valve-in-valve mitral valve replacement. J Thorac Cardiovasc Surg Tech. 2020;3:154-6.

\footnotetext{
From the Division of Cardiac Surgery, Department of Surgery, Cardiovascular Center at UCLA, David Geffen School of Medicine at UCLA, Los Angeles, Calif. Disclosures: The author reported no conflicts of interest.

The Journal policy requires editors and reviewers to disclose conflicts of interest and to decline handling or reviewing manuscripts for which they may have a conflict of interest. The editors and reviewers of this article have no conflicts of interest.

Received for publication July 13, 2020; revisions received July 13, 2020; accepted for publication July 14, 2020; available ahead of print July 20, 2020.

Address for reprints: Richard J. Shemin, MD, Ronald Reagan UCLA Medical Center, David Geffen School of Medicine at UCLA, 100 UCLA Medical Plaza, Suite 730,

Los Angeles, CA 90095 (E-mail: Rshemin@mednet.ucla.edu).

JTCVS Techniques 2020;3:157

2666-2507

Copyright (C) 2020 The Authors. Published by Elsevier Inc. on behalf of The American Association for Thoracic Surgery. This is an open access article under the CC BY-NCND license (http://creativecommons.org/licenses/by-nc-nd/4.0/).

https://doi.org/10.1016/j.xjtc.2020.07.016
} 